\title{
In Defence Of Modal ESSENTIALISM
}

Jonathan Livingstone-Banks 


\begin{abstract}
Kit Fine's arguments in Essence and Modality are widely accepted as being a decisive blow against modal essentialism. A selection of replies exist that have done little to counter the general view that modally construed essence is out of touch with what we really mean when we make essentialist claims. I argue that Fine's arguments fail to strike a decisive blow, and I suggest a new interpretation of the debate that shows why Fine's arguments fall short of achieving their goal.
\end{abstract}

Key Words: Essence, Neo-Aristotelian, Real Definition, Modality, Fine 


\section{In Defence Of Modal ESSENTIALISM}

\section{Introduction}

Herein I defend modal essentialism from Kit Fine's (1994) arguments as presented in Essence and Modality. In doing so I discuss how one should interpret the debate between modal essentialism and Fine's own position, which I call neo-Aristotelian essentialism. ${ }^{1,2}$

Modal essentialism states that essentialist claims should be understood (one way or another) in terms of necessity. That is, that essence is at its heart a modal notion. Fine's arguments against modal essentialism take the following form. There is a base of essentialist facts that inform us regarding essence. Whilst Fine may not explicitly admit as much, our access to this base seemingly comes through intuitive understanding. Through this understanding we can say that we have a well understood notion of essence, to which candidate theories must conform. ${ }^{3}$ According to Fine, modal essentialism founds a group of essentialist facts that is extensionally infelicitous with the group established by our understanding of essence. There are essentialist claims that are true under modal essentialism that are not true according to our intuitive understanding of essence. Because essence, so understood, cannot be adequately explained in modal terms, modal essentialism must be false. I argue that Fine's attempts to demonstrate the extensional inaccuracy of modal essentialism are not decisive, and that this interpretation of the debate is flawed. ${ }^{4}$

I characterise Fine's notion of essence as being based on intuition. There are two ways that we might interpret these intuitions. On the one hand, they might be pre-philosophical opinions. This raises the epistemic question of how we have access to essentialist facts sufficient for our intuitions to be an accurate guide to essence, and the methodological question of how we can insist that any theory

\footnotetext{
${ }^{1}$ Neo-Aristotelian because it makes use of real definitions, a notion often attributed to Aristotle. Cf. Fine (1994 2-3), Hale (2013 152 fn.17), and Koslicki (2012b) on the link with Aristotle. Neo-Aristotelian essentialist positions are also presented in, inter alia, Correia (2006), Lowe (2008), Oderberg (2007), and Shalkowski (2008).

${ }^{2}$ Fine presents this position over a series of papers. See Fine (1994; 1995a; 1995b; 1995c; 2000; 2007; 2015).

${ }^{3}$ By 'well understood' I mean that we have a confident grasp of what we take to be instances of true essential predication, just as we have a confident grasp of what we take to be instances of composition. Of course, metaphysical theories differ in what they claim to be instances of composition, and the fashion for bullet-biting in mereology is well established, but when asked if some objects compose, we have a pre-theoretical understanding that will answer 'yes' or 'no' in most normal situations.

${ }^{4}$ Alternative responses from Della Rocca (1996), Gorman (2005), and Zalta (2006) are effectively dismantled by Wildman $(2013 ; 2016)$ in favour of his own response. He (and Cowling [2013], separately) suggests that the modal essentialist adopt a condition that only sparse properties can be essential to objects. Whilst this may successfully evade Fine's criticisms (although, see Skiles [2015], it does so by accepting a hyperintensional distinction that, I take it, is similar in spirit to Fine's essentialism. Correia (2007) gives an in principle demonstration that a modal theory of essence is possible, but insufficiently motivates adopting the position (see also Fine's [2007] response to Correia). The responses I present here are for those who more strictly adhere to the motivations of modal essentialism, either by resisting Finean intuitions, or by showing that modal essentialism can match them without resorting to hyperintensional notions.
} 
of essence be beholden to those intuitions (especially before we have a satisfactory answer to the epistemic question). On the other hand, we might understand those intuitions as being philosophical in nature, in which case the examples Fine presents in his critique of modal essentialism should not be interpreted as arguments against modal essentialism, for to do so is merely to beg the question in favour of the neo-Aristotelian understanding of essence. Rather, we should understand them as definitive of the neo-Aristotelian notion.

I think that we should be understanding these cases as definitive of the neo-Aristotelian notion of essence, but if we are to take Fine's critique at face value, and afford it the charity of not labelling it question begging, then we should understand Fine's position as being motivated by pre-theoretical intuitions, rather than philosophically informed ones.

Given this understanding of the intuitions behind Fine's position, I propose that the debate on essentialism, as construed above, is wrong-headed. To conclude that there is such a well understood notion of essence based on our pre-philosophical opinions is premature. Instead of taking the debate to be between two rival accounts of a well understood notion, against which extensional inaccuracy is damning criticism, I propose that i) there may in fact not be such a well understood unified notion, and ii) even if there is, this need not be so constraining a factor as it is often taken to be. To compare with mereology, if our pre-theoretical notion of composition were taken to be so well understood, and if extensional adherence to this notion were held to such importance, then the theoretical landscape in the metaphysics of mereology would be very different indeed, and not, presumably, for the better.

The debate between modal and neo-Aristotelian essentialism might be better interpreted not as between competing accounts of one well understood notion, but rather as between rival theoretical notions of essence loosely corresponding to our pre-philosophical opinions. Rather than there being a firmly held set of beliefs that we have to account for, our thoughts about essence are more of a loose idea about what it is to be certain things. As such, our theory has just as many gaps to fill in as it does beliefs to uphold, and just as in our theories in physics and biology, revisionary conclusions are not defeaters in and of themselves. If one interprets the debate as I suggest then Fine's arguments can be characterised as being definitive of a neo-Aristotelian notion of essence, rather than as critical of the modal account. ${ }^{5}$ Even so, I show that even if one interprets the debate as Fine does, the arguments he provides are far from conclusive.

I first present Fine's criticisms of modal essentialism. In Section Three I present and develop Fine's position as relevant to his discussion of modal essentialism and the opposition between the two. In Section Four I respond to Fine's criticisms in light of the developments he avails himself of in his own

\footnotetext{
${ }^{5} \mathrm{An}$ interesting related question is whether this interpretation of the debate is appropriately applied to discussions of the metaphysics of dependence, which is often discussed in parallel to essence.
} 
position, and my own proposed interpretation of the debate. I conclude that Fine's arguments fail to decisively demonstrate the extensional inaccuracy of modal essentialism, and that to see the best in Fine's work, the reader should interpret the debate on essentialism as I suggest.

\section{Against Modal Essentialism}

In support of neo-Aristotelian essentialism, Fine argues against two forms of modal essentialism:

(CATEGORICAL) An object $a$ is essentially $\mathrm{F}$ iff $a$ is necessarily $\mathrm{F}$.

(CONDITIONAL) An object $a$ is essentially $\mathrm{F}$ iff $a$ is necessarily $\mathrm{F}$ if $a$ exists.

Fine's argument has two steps. He first argues that the proposed modal accounts of essence fail to produce a notion that is co-extensional with essence. To do this he gives four cases where there are true necessities, but no true essential predications. Fine then argues that there is reason to think that no such account could work, because of key differences between the notions of necessity and essence (which the four cases reveal). Fine's $(1994,8)$ reasons for the latter claim lead him to assert that rather than essence being a special case of metaphysical necessity, the converse is true, and metaphysical necessity is a special case of essence.

CASE 1: Consider any necessary proposition, for example that $2+2=4$, or that there are infinitely many prime numbers. These claims are necessary if true. Thus, for either 'it is necessarily the case that this truth should hold if Socrates exists' (Fine 1994, 5). As such, under modal essentialism it is essential to Socrates that $2+2=4$. However, that $2+2=4$ has nothing to do with what Socrates is, so we should resist the claim that it is essential to him. Furthermore, as Fine agrees that true essential predications are also necessary, the essence of any object will (according to either modal account) include the entirety of the essence of every other object.

CASE 2: All true identity and non-identity claims are necessarily true. ${ }^{6}$ Socrates is distinct from the Eiffel tower; he is therefore necessarily distinct from it. However, Fine $(1994,4)$ rejects the claim that Socrates is essentially distinct from the Eiffel Tower, 'for there is nothing in his nature that connects him in any special way to it'. The pre-theoretical understanding of essence compels one to only accept a predication as being essential when it says something about what it is to be the thing of which it is being predicated. Whilst it may be necessary that Socrates is distinct from the Eiffel Tower, this doesn't

\footnotetext{
${ }^{6} \mathrm{Here}$ and throughout, when talking of identity and non-identity claims I intend them to hold between things as referred to rigidly. This excludes from consideration contingent identity and non-identity claims such as 'Socrates is the teacher of Plato' and 'Socrates is not the founder of the Academy', both of which are true, but might have been false.
} 
tell us anything about the nature of Socrates. As such, Fine sees no reason why the Eiffel Tower should feature in Socrates' essence.

CASE 3: Trivially, it is necessary that Socrates exist if he exists, so according to CONDITIONAL, Socrates essentially exists. Fine claims that this is absurd. He is willing to countenance things that exist essentially, calling such things 'essential beings', but reserves such status for the likes of God. Even Socrates is excluded from this elite group.

CASE 4: Socrates is both necessarily a member of his singleton set $\{$ Socrates\}, and necessarily a member of \{Socrates\} if he exists. As such, under either modal account he is essentially a member of \{Socrates\}. Fine denies this. Whilst it is necessary that Socrates $€\{$ Socrates\} (Fine does not question the necessity of the modal account, only its sufficiency), Socrates' set memberships do not tell us anything about what it is to be Socrates, so it is not essential to him that he be a member of \{Socrates\}, or of any other set. In contrast it is essential to \{Socrates\} that it contain Socrates as a member, because containing Socrates is what makes \{Socrates\} what it is. This displays an asymmetry in essence that is not present in necessity. It is essential to \{Socrates\} to contain Socrates, but not essential for Socrates to be a member of \{Socrates\}. This asymmetry cannot be accounted for by either of the modal accounts and, as such, essence cannot be co-extensional with the modal notions they employ.

Fine identifies the common factor in these cases as the asymmetry that is lacking in the necessary connections, but present in the corresponding essentialist connections. This asymmetry makes essence more fine-grained ${ }^{7}$ than necessity, rendering necessity unable to provide an explanation of essence.

It is worth noting the significance of Fine's strategy. Fine presents an understanding of essence seemingly based on our pre-philosophical opinions, insisting that any account of essence should correspond to this understanding. This effectively rules out revisionary accounts of essence. Yet there is little reason to think that we have sufficient epistemic access to the essentialist facts for the way we talk and think about essence in everyday life to fully indicate what the essentialist facts are. It's not clear that Fine's idea of a well-defined single notion of essence is adequately supported by the way we think of and use essentialist claims. The essentialist language we use doesn't seem to indicate any special understanding or insight into the underlying metaphysics, and thus is a poor guide to it. This jeopardises the efficacy of his argument against modal essentialism.

${ }^{7}$ No pun intended. 
In addition, by relying on our pre-philosophical opinions about essence, Fine's strategy depends on rejecting certain essentialist claims (that Socrates is essentially a member of $\{$ Socrates\}, for example) on the grounds (to put it somewhat unflatteringly) that they sound odd. However, there is a significant difference between what is odd to say and what is false. In defence against Fine's arguments, the modal essentialist can appeal to the distinction between what is sensible or germane to say in everyday discourse, and what is true by our metaphysical theory. I contend that, since our pre-philosophical opinions do not accurately single out a complete and well understood notion of essence, some revisionary consequences should be acceptable in a theory (or at the very least, should not be a damning criticism in their own right). For instance, whilst it certainly sounds odd to say that there are no such things as tables, or monkeys, we do not take this as decisive reason to reject mereological nihilism. We may think it counts against it, but it wouldn't do to dismiss the position out of hand as asserting falsities. ${ }^{8}$ When the results of a theory of essence sound odd or contrast with our pre-theoretical understanding, we should bear in mind the distinction between what merely sounds odd, and what is really false.

Fine takes his understanding of essence to be a safe assumption. He also makes the methodological assumption that extensional infelicity to this understanding of essence is a decisive objection to any rival theory of essence, thus disqualifying revisionary positions. I challenge the safety of these assumptions. Our pre-philosophical essentialist opinions do not suffice in establishing a complete and well-understood notion of essence, and as such there is no one standard against which candidate theories should be measured. To argue against a theory of essence because it is extensionally infelicitous with our pre-philosophical opinions is methodologically under-motivated, and to adopt the same strategy with philosophical intuitions risks question begging.

\section{Neo-Aristotelian Essence}

\subsection{Essence as Real Definition}

According to Fine, essences act as the ontological equivalent of linguistic definitions. Just as we can provide linguistic definitions for terms, stating what those terms mean, essences act as the real definitions of objects, stating what those objects are. The definition of a term is the set of definitional truths that concern that term. Fine $(1994,11)$ takes these definitional truths to be true in virtue of the meanings of their defined terms. Just as the definition of a term is the set of propositions that are true

${ }^{8}$ Of course, the mereological nihilist is able to offer translations of our everyday claims about tables and monkeys in terms of arrangements of mereological simples, thus alleviating the tension of rejecting composition. A revisionary essentialist might be expected to do further work to explain why we have the essentialist beliefs or intuitions we do if the actual essentialist landscape is significantly different. 
in virtue of that term meaning what it does, the essence of an object is the set of propositions that are true in virtue of that object being what it is (the 'identity' or 'nature' of that object) (Fine 1995a 55; 1995b 275). ${ }^{9}$ Fine (1995b 273) takes the ' $\ldots$ is true in virtue of the nature of ...' locution to signify an unanalysed relation between a proposition and an object; call this relation TIVON. ${ }^{10}$ A proposition $\mathrm{P}$ bears TIVON to an object (or group of objects) when that proposition is true because those objects are the objects that they are. ${ }^{11}$

Having sketched the basics of Fine's account, in the next section I discuss an important development of it that will be relevant to the defence of modal essentialism.

\subsection{Consequential/Constitutive Essence}

The problem posed by Case 1 stems from unwanted propositions creeping into the essences of things to which they are irrelevant. There is the potential for an analogous problem for the Finean essentialist that stems from logical consequence. Before discussing how Case 1 can be addressed, it is important to first examine the role of logical consequence in Fine's theory of essence. Fine (1995a) asks if essential predication is closed under logical consequence. That is, when Curie's being essentially $F$ logically implies that Curie is G, is Curie essentially G? If the answer to this question is 'yes' then the Finean essentialist encounters the same problem as the modal essentialist, in that the Finean essentialist will be forced to include propositions in the essences of objects that our pre-philosophical opinions insist we exclude. In particular, three forms of proposition are logical consequences of Socrates being $F$.

(1) $<$ Curie is $\mathrm{F}$ or $\mathrm{H}>$, where $\mathrm{H}$ is some arbitrary predicate

(2) $<$ Curie is F or not F>

(3) <Curie is $\mathrm{F}$ and such that I $>$, where I is an arbitrary necessity

Fine criticises the modal account of essence on the grounds that it is extensionally inaccurate; it includes propositions in the essences of objects that don't say anything about what those objects are. Propositions like 1, 2, and 3 are problematic for just the same reasons. If Fine cannot exclude them from the essences of objects then he will be subject to a tu quoque response from the proponents of

\footnotetext{
${ }^{9}$ Fine considers essence in two ways: in terms of true propositions concerning an object, and in terms of objects having properties. Here I remain neutral concerning which characterisation to take, and the metaphysical ramifications that come with them. However, for the sake of consistency, and ease of discussion I will continue to use the propositional form throughout.

${ }^{10} \mathrm{An}$ interesting, and potentially problematic, issue arises from taking TIVON as primitive. It is not clear what relation, if any, TIVON bears to truth simpliciter. One might think the former is a special case of the latter, but if TIVON is taken as primitive then this cannot be the case, nor can any other explanation of what the two notions have in common.

11 One might take TIVON to be a species of essential dependence as described in Tahko \& Lowe (2015)
} 
modal essentialism. For this reason, Fine must resist logical closure. To do so, he distinguishes between constitutive and consequential conceptions of essence (Fine 1995a 57).

It is constitutive of $a$ 's essence that $a$ is $\mathrm{F}$ iff $a$ is essentially $\mathrm{F}$, and that $a$ is $\mathrm{F}$ is not a logical consequence of $a$ being essentially $\phi$ (where $\phi$ is any 'more basic' part of $a$ 's essence).

It is consequential of $a$ 's essence that $a$ is $\mathrm{F}$ iff $a$ is essentially $\mathrm{F}$, and that $a$ is $\mathrm{F}$ is a logical consequence of $a$ being essentially $\phi$ (where $\phi$ is any 'more basic' part of $a$ 's essence).

Constitutive essence is taken to be 'directly definitive of the object'. It is this, and not consequential essence, that is of interest and importance to the metaphysician. By adopting the constitutive, and rejecting the consequential conception of essence, the problematic closure propositions do not feature in objects' essences. This allows Fine to maintain the definitive characterisation of essence.

Fine recognises a significant concern with the distinction. It is difficult to know both where the boundary between constitutive and consequential essence should lie, and how it should be decided upon. This is more than just an epistemic problem. In order to maintain an intelligible characterisation of the constitutive conception of essence, we need a metaphysical definition of what a 'more basic' part of an object's essence is. ${ }^{12}$ Without any apparent way to draw this line using tools already available to him, Fine has little choice but to either introduce more ideology to make the distinction, or to abandon constitutive essence. Thus, short of finding a way to draw such a distinction safely, Fine suggests that we retain the consequential conception of essence at the expense of the constitutive. ${ }^{13}$

Fine claims that there is a way to retain the benefits of the constitutive conception whilst retaining the conceptual economy of the consequential conception. He says that we can generalise away problematic propositions that are gained by logical closure, rendering consequential essence fit for purpose. ${ }^{14}$ It is a part of Curie's consequential essence to be $\mathrm{F}$ or not $\mathrm{F}$, but it is a part of every other object's consequential essence as well. As such, it can be effectively excluded from consideration because it can be generalised out of Curie's consequential essence. Likewise, if the generalisation of a proposition is contained in the consequential essence of an object, then both the proposition and its generalisation can also be generalised out. Fine claims that this is a non-ad hoc way of excluding problematic propositions from objects' essences. The claim is that the essential propositions of interest are those that cannot be generalised away. We can present the principle like so:

\footnotetext{
${ }^{12}$ One could interpret Cowling's (2013) and Wildman's (2013) use of the sparse/abundant property distinction as an attempt to do just this.

${ }^{13}$ Presumably Fine doesn't intend to keep the consequential conception of essence as is, as the definition he gives also mentions 'more basic' parts. I will not press the matter here as it seems safe to assume that an alternative formulation could be found.

${ }^{14}$ Koslicki (2012a) interprets this move as an attempt to redefine constitutive essence in terms of consequential essence.
} 
GENERAL: Any proposition that is part of the consequential essence of an object can be generalised away either if it is part of the essence of every object, or if the generalisation of that proposition is also contained in the consequential essence of the object (Fine 1995a 59; 1995b 277-278).

An example of the first disjunct: everything is such that it is $F$ or not $F$, and as such being $F$ or not $F$ can be generalised out. An example of the second disjunct: the generalisation of $\langle$ Curie $=$ Curie $\rangle$ is $\langle(x)(x=x)>$. $\langle$ Curie $=$ Curie $>$ is necessarily true, and as such will feature in the essence of any object $a$ because it is a logical consequence of any proposition in $a^{\prime}$ s essence. However, $\langle(x)(x=x)>$ is contained in the consequential essence of $a$ (because it too is metaphysically necessary), so both it and any specific instance of it can be generalised away.

Whilst successful in excluding 2 ( $<$ Curie is $F$ or not $F>)$, the generalisation strategy does nothing to exclude 1 ( $<$ Curie is $\mathrm{F}$ or $\mathrm{H}>$, where $\mathrm{H}$ is some arbitrary predicate) or 3 (<Curie is $\mathrm{F}$ and such that $\mathrm{I}$, where $\mathrm{I}$ is an arbitrary necessity) from Curie's essence, as neither feature in the essences of everything (assuming that $F$ is something non-universal, such as 'is human'), nor do generalisations of 1 or 3 feature universally in the essences of everything. ${ }^{15}$ This is because, since Curie only exists contingently, neither is necessarily true. The question remains as to how to go about excluding 1 and $3 .{ }^{16}$

\subsection{The Role of Logical Concepts}

Fine (1994 8) himself has developed the resources for overcoming this problem, specifically in his claim that logical concepts have essences, and that these are the source of logical necessities. He is committed to the essences of logical concepts in so far as he uses them in his essentialist theory of necessity. ${ }^{17}$

If the TIVON relation can hold between propositions and logical concepts, then logical concepts must be taken into consideration in the above problem. Because 1 and 3 are logical consequences of

\footnotetext{
${ }^{15}$ Unless one is willing to include second order generalisations, where the predicates are replaced with predicate variables. Suffice to say, such a response would be far too strong, excluding much more than is desirable. For every $x$, necessarily $\phi x$ (where $\phi$ is a predicate variable), but if $\phi x$ and every instance of it can be generalised out, then it follows that Curie isn't essentially human. Further, one might think that 1 and 3 can be generalised away on the grounds that it is true of everything that some arbitrary predicate $\mathrm{H}$ or necessity I might be latched onto its essence (because of the natures of disjunction and necessity respectively). As such, we could simply generalise away any propositions introduced through such methods. However, this is tantamount to ruling out propositions introduced through logical closure altogether, and rejecting the consequential notion of essence entirely.

${ }^{16}$ Koslicki (2012a) also presents a counterexample to Fine's generalising strategy, using metaphysical necessity. Because it is necessary that the number 2 is not a member of \{Socrates\}, the number 2 cannot be generalised out of the essence of \{Socrates\}. This serves the same purpose as 1 and 3 in my argument, except that 1 and 3 are only contingently true, making them harder to exclude without resorting to ad hoc rules.

${ }^{17}$ Fine says nothing about what kinds of things these logical concepts are, but since logical concepts have essences, they must be viable relata for the TIVON relation.
} 
Curie being F, they do not bear TIVON to Curie alone, but rather to plurals of Curie and certain logical concepts. For example, 1 bears TIVON to the plural of Curie and disjunction, and 3 bears TIVON to Curie, conjunction, and whatever it is that I is true in virtue of. This provides us with just the resource we need to exclude unwanted propositions from Curie's essence. We can restrict consequential essence appropriately by excluding any proposition that does not bear TIVON solely to Curie. This means that 1 and 3 are essential to the plurals, but not to Curie, or any of their other proper parts, alone. ${ }^{18}$ Fine is already committed to reifying logical concepts (at least to the extent that they can be relata for TIVON), so the ontological cost (for Fine at least) is minimal.

This reveals a potential concern. If the logical consequences do not bear TIVON to Curie alone, but to Curie and the relevant logical concepts, then is it not the case that such a plurality must also include the concept of logical consequence itself ${ }^{19}$ Otherwise, what will take one from the essences of Curie and disjunction to 1 ? Furthermore, what of Curie's essence in the first place? Curie's essence is made up of the propositions that bear TIVON to her. TIVON is not the same as logical consequence, but in the analogy between essence and analyticity, TIVON plays the same role in real definition as logical consequence does in nominal definition. Would it not be the case that there are no propositions essential to Curie alone, but rather only propositions essential to the plural of Curie and the TIVON relation? The response looks in danger of excluding too much.

In response we must first concern ourselves with the nature of the essences of logical concepts. Fine suggests that the essences of logical concepts are inferential in character, rather than propositional. The essences of logical concepts like disjunction are not made up of propositions of the form <if $P$ then $P$ or $Q>$. They are made up of the inferences licensed by the concept, such as the inference from $\mathrm{P}$ to $\mathrm{P}$ or $\mathrm{Q}$ (Fine 1995a 58). ${ }^{20}$ For example, the essence of the logical concept corresponding to one of the logical connectives might be made up of the introduction and elimination rules for that connective. However, as Correia (2012 8) points out, there are some features of a logical concept's essence that are propositional in nature, for instance that it is a concept. Therefore, we should distinguish between the properly logical essence of a logical concept, which is inferential in nature, and the non-properly logical essence, which is propositional in nature.

Securing the inferential character of the essences of logical concepts removes the need to posit logical consequence as a concept in its own right. ${ }^{21}$ Rather than having the essence of Curie and the essence of disjunction, and then needing something in addition to get from them to a claim like 1 , the

\footnotetext{
${ }^{18}$ This also successfully excludes the Koslicki (2012a) counterexample.

${ }^{19}$ Instead of jumping straight to logical consequence, one might include some conditional rule like modus ponens. However, such an approach would lead to a Carroll (1895) style regress.

${ }^{20}$ Exactly what inferences are supposed to be is not made clear, but Fine allows himself them, so I shall as well. Nor will I consider the potential complications that may arise from this move. For example, the inferential nature of the essences of logical concepts implies that the TIVON relation must also be a relation between inferences and concepts.

21Though Fine characterises the essences of logical concepts as inferential for different reasons (see Fine 1995a 57).
} 
inclusion of disjunction licences the inference itself (by the inferential character of its essence). In effect, logical consequence is 'built into' the logical concepts. As such, 1 bears TIVON to Curie and disjunction, rather than Curie, disjunction, and logical consequence. I contend that if this is the case for logical consequence, then the same can be the case for the TIVON relation.

One might think that because the TIVON relation is metaphysical in nature, not logical, it acts differently to logical consequence. Whatever it is about the TIVON relation that links objects to propositions, it is not logical consequence. However, TIVON is modelled on logical consequence; doing a metaphysical analogue of the task logical consequence does in definition. The proposal is akin to claiming that, just as the notion of logical consequence is built into the logical concepts (via the inferences that they license), so too TIVON is built into everything, such that certain propositions will be true, simply because an object is the object that it is. This fits with the initial characterisation given of TIVON above. If this is accepted then the problem of excluding 1,2 , and 3 is resolved. $1-3$ are not essential to Curie, because they do not bear TIVON to Curie alone, but rather to plurals containing Curie. This response does not go too far, because (now that TIVON is 'built in' just as logical consequence is) propositions like <Curie is human $>$ are essential to Curie alone.

\subsection{Reviving Constitutive Essence}

Using this strategy to merely save Fine's jury rigging of consequential essence is under-ambitious. Understanding logical consequence and the TIVON relation in this way allows us to properly demarcate the constitutive conception of essence. One can take the constitutive essence of an object to be the class of propositions that bear TIVON to that object alone. The consequential essence of that object is the class of propositions that bear TIVON to the pluralities that the object is a part of. Defining constitutive essence in this way provides the Finean essentialist with a way to deny that essence is closed under logical consequence. It does not require the introduction of any new ideology that the Finean is not already committed to. It ensures that constitutive essence meets the Finean criteria set out in the introduction. The primitive TIVON relation is well suited to this role, ensuring that essence is co-extensive with our (alleged) pre-theoretical understanding of essence.

Establishing the relationship between constitutive and consequential essence and settling the issue of logical closure leaves us in a position to reply to Case 1. 


\section{Responding to Fine}

\subsection{Case 1}

Case 1 claims that, according to modal essentialism, it is essential to Socrates that $2+2=4$, or that the Eiffel Tower is a tower, because Socrates is necessarily such that any necessity is true. Fine denies that such claims have anything to do with the essence of Socrates, so modal essentialism is extensionally inaccurate.

A Finean generalisation response, claiming that because everything is such that $2+2=4$ it can be safely excluded, would be too strong, excluding more than is desirable. Object $x$ (and indeed everything) is essentially such that $a$ is essentially F, because, as Fine (1994 5) says, essentialist claims are themselves necessary if true. Since everything essentially has the property of being such that $a$ is essentially $F$, it is generalised away in the fashion that Fine allows. However, this ought to be resisted because it is still important to $a$ that it be essentially $\mathrm{F}$.

This problem can be avoided. Whilst 'being such that $a$ is essentially $\mathrm{F}^{\prime}$ is generalised away, 'being essentially $\mathrm{F}^{\prime}$ is not generalised away from $a$. As such, $a$ remains essentially $\mathrm{F}$, but nothing else is essentially such that $a$ is essentially $\mathrm{F}$. This can be better elucidated by introducing an essentialist operator ' $\varepsilon$ ' that modifies predicates to form complex essentialist predicates of the form ' $\varepsilon F^{\prime}$ (... is essentially-F). ${ }^{22}$ Whilst it is true that $(x)([\varepsilon \lambda y(F a)], x)$ (that everything is essentially such that $a$ is $\left.\mathrm{F}\right)$, it is not true that $(x)([\varepsilon \lambda y(\mathrm{Fy})], x)$ (that everything is essentially such that it is $\mathrm{F}$ ), so $a^{\prime}$ 's essentially being $\mathrm{F}$ $([\varepsilon \lambda y(\mathrm{Fy})], a)$ is not generalised away, even though $a^{\prime} \mathrm{s}$ 'essentially being such that $a$ is $\mathrm{F}^{\prime}$ is generalised away.

Fine anticipates a generalisation response to Case 1. He claims that whilst excluding essential properties that are held by everything would resolve the problem, it could be easily reinstated by 'conjoining the given degenerate essential property with one which was not degenerate' (19946). This is true. Instead of being essentially such that $2+2=4$, Socrates is essentially such that he is human and $2+2=4$ (precisely the kind of property we confronted Fine with in Section Three).

A potential defence against this variation of the problem comes from Della Rocca (1996). Della Rocca's characterisation of essence includes a generalisation approach that precludes any trivial property from featuring in the essence of an object. He introduces a notion of triviality which, whilst perhaps not explicitly writing with Fine's work in mind, could be taken to circumvent this revival of the

\footnotetext{
${ }^{22}$ This is one of the ways that Fine (1995a) formulates essentialist claims. I use different notation to single out this operator as neutral between different interpretations of essence. Whilst Fine uses his operator to express neo-Aristotelian essentialist claims, there is an appropriate understanding of these sentences in purely modal terms in the form of Wiggins' (1976) de re must. Here, the 'essentially' operator can be interpreted as a necessity operator ranging over the predicate (in line with how Wiggins thinks necessity de re should be understood), and as such, using it does not jeopardise modal essentialism introducing primitive essence.
} 
problem (Della Rocca 1996 3). According to Della Rocca, an object has a property trivially if it is either universally instantiated, or follows directly from the object having some other property that is universally instantiated. This means that, for example, an object $a$ is not essentially identical to $a$, because it follows directly from the property of self-identity, which is universally instantiated. However, as Wildman (2016 3) points out, this fails to provide sufficient response to the revived problem; such a rule would result in the exclusion of all candidate essential properties. Consider Curie's humanity. This follows directly from the universally instantiated property of being human-ifCurie $((\lambda x)$ (if $x=$ Curie then $x$ is human)). Everything is such that it is human if it is Curie, and because Curie's humanity follows from a universally instantiated property, it must be excluded. The same can be reconstructed for any candidate property. This is, suffice to say, undesirable.

What of Fine's own generalisation response? Fine claims that the inability to rigorously demarcate constitutive essence is not a problem because consequential essence can be rendered adequate once the universally instantiated properties have been generalised away. Fine's generalisation proposal does not go as far as Della Rocca's, and does not inherit those problems, but it is in no better position than the generalisation responses he anticipates in Essence and Modality. After all, being essentially such that she is human and $2+2=4$ follows from Curie's essence under the neo-Aristotelian interpretation, just as it does from the modal one.

The neo-Aristotelian essentialist can avoid this jeopardy by adopting the characterisation of logical concepts as inferential in nature. Further, they can adopt the definition of constitutive essence proposed in Section 3.4, and not worry about such problems at all. It is not clear what relief might be gained for the modal essentialist by adopting Fine's characterisation of logical concepts, but perhaps they might avoid the problem by making their own distinction between constitutive and consequential essence along similar lines. It is clear that the modal essentialist cannot adopt my proposed definition of constitutive essence because it incorporates the distinctly neo-Aristotelian TIVON relation. What of the original form that Fine presents? This would successfully exclude the problematic propositions. However, it inherits the problems that originally led Fine to favour the consequential account over the constitutive. It is not clear how our theory should distinguish between the 'more and less basic' properties. This problem is just as pronounced for the modal essentialist. Furthermore, the modal essentialist taking this form of response may be accused of presupposing the pre-theoretical content of neo-Aristotelian essence. By distinguishing between the properties that tell us what the object is, and those that merely follow from the 'proper' essential properties, the modal essentialist risks assuming a level of fine-grainedness that necessity is not fit to bestow. Does this not mean that essence is no longer intensional, but hyper-intensional? If an adequate selection criterion can be found that distinguishes between the constitutive and consequential essence and can be expressed in 
modal terms then this does not entail a move to hyper-intensionality (and neo-Aristotelian essence), but rather to a restricted intensional notion (much as the conditional modal account provides). Such a criterion can be found. Here I suggest that the modal essentialist can adopt a constitutive notion of essence, defined thus:

CONSTITUTIVE*: Proposition $\mathrm{P}$ is part of $a$ 's constitutive essence iff $\mathrm{P}$ is true at every world at which $a$ exists, and at every world where $a$ exists, $a$ and $a$ alone is the thing that makes $\mathrm{P}$ true. ${ }^{23}$ It makes sense to think that in a world $w$, some propositions will be true because of some things, rather than others. For example, if it is true at $w$ that the Eiffel Tower exists, it is true because the Eiffel Tower (or its counterpart in w) exists in $w$. Likewise, if it is true that Curie was left handed, it is true because of Curie. Note that the 'truth because of' relation here is different from the TIVON relation, and is more like a truth-maker relation. ${ }^{24}$ The intended relation is the kind by which Socrates is what makes it true that 'Socrates is human', but it is not sensitive in the way that TIVON is, so Socrates is also what makes it true that 'Socrates is bearded'. Socrates makes the former true in every world that he exists in, but does not make the latter true in every world he exists in. Yet in the worlds in which it is true, it is true because of him. One might call such a position 'targeted modal essentialism'.

Singling out the propositions that are true because of Socrates in every world he exists in singles out those propositions that make up his constitutive essence. What's more, those propositions are selected for the right reasons rather than by some arbitrary or ad hoc process. Far from smuggling hyper-intensionality into the account, this approach is in the spirit of modal essentialism. I take the motivation for modal essentialism to be the desire to account for certain counterfactuals we take to be true about objects, specifically those about how that object could or could not have been. The essence of an object can be understood as its modal profile. However, what modal essentialist accounts currently identify is the modal profile of the worlds singled out by an object's presence in them. When I ask what change Socrates could survive, I am asking specifically about Socrates (and perhaps his counterparts). I am not asking about the worlds Socrates exists in. By concerning ourselves with just the propositions that are true because of Socrates in each world he exists in, we identity his modal profile, not that of any world. In addition, adopting targeted modal essentialism allows one to avoid the potential counter-example to modal essentialism whereby 'Socrates is a man'

\footnotetext{
${ }^{23}$ Depending on one's metaphysics of properties, this may be problematic. If to have a property is to instantiate a universal, then there will never be one thing in virtue of which that thing has the property (except for homological properties, such as the universal of being a universal).

${ }^{24}$ The 'because of' relation used here should be expanded upon with some more detailed theory of truth-making. Whilst it is beyond the scope of this paper to give an in-depth examination of what the 'because of' relation must be like, it is clear that the position presented here will be incompatible with some notions of truth-making (for instance, those that deny that absolute necessities have truth-makers), and thus of limited appeal for their proponents. Of particular importance will be demonstrating that 'because of' is not a hyper-intensional notion. Furthermore, CONSTITUTIVE* might be alternatively phrased in terms of the instantiation of properties rather than the truth of propositions.
} 
is true, but for reasons other than Socrates' being there (e.g. worlds that contain a contradiction from which anything can be inferred).

Adopting CONSITUTIVE* will incur some revisionary consequences. ${ }^{25}$ Most notably, it is a potentially significant limitation of CONSTITUTIVE* that it appears to be incompatible with constitutively essential relations. In response to this, the modal essentialist can claim that whilst relations cannot feature in constitutive essence, they do feature in consequential essence. This may seem unsatisfactory. ${ }^{26}$ After all, it seems constitutive of $\{$ Socrates\} that it have Socrates as a member. However, this relies on the intuitive meaning of the term 'constitutive' as originally presented by Fine. On the modal account, constitutive essence just is the modal profile of that individual, whilst the consequential essence is the modal profile of the thing as related to other objects. The terms 'constitutive' and 'consequential' are vestigial relics of Fine's presentation, and are now somewhat misleading. ${ }^{27}$ One might even rename them the 'individual' and 'relational' forms of essence respectively. This of course comes with the limitation that the essential relationship between Curie and her parents is of the same level as her relationship with the number 2, but part of the goal of this discussion is to elucidate the essential status of claims by the modal essentialist's own lights, rather than trying to squeeze modal essentialism into the shape expected of neo-Aristotelian essentialism. If the motivations for neo-Aristotelian essentialism are pre-philosophical, then when considering this kind of revisionary consequence, we can (just as, say, the mereological nihilist) once again appeal to the difference between what is germane in everyday conversation, and what is true according to our metaphysics. Such a theory may not ultimately do everything that we need a theory of essence to do, but we ought not to dismiss it out of hand merely for being revisionary. If the neo-Aristotelian intuitions are philosophical, then it is not enough to reject modal essentialism on the grounds that it disagrees with neo-Aristotelian intuitions without first giving further argument for those intuitions.

By adopting an appropriate definition of constitutive essence such as the one presented above, the modal essentialist can respond to Case 1 by excluding the problem cases because they do not feature in the constitutive essence of the thing in question.

\footnotetext{
${ }^{25}$ These may relate in particular to the essences of logical or mathematical concepts, where the source of truth for various claims is not entirely clear. Suffice to say, I do not take revisionary consequences to be defeaters in their own right, but the implications of adopting CONSITUTIVE* would need to be investigated in detail.

${ }^{26}$ There is no reason why CONSITUTIVE* could not be supplemented by a further principle that could account for essential relations. However, exploring what form such a principle might take is beyond the scope of this discussion.

${ }^{27}$ Alternatively, there is some precedent for rejecting essentialist relations altogether. Adams (2016) and Denby (2014) both argue that essential properties must be intrinsic.
} 


\subsection{Case 2}

Case 2 claims that because identity and non-identity claims are necessarily true, according to modal essentialism Socrates is essentially distinct from the Eiffel Tower. Fine denies that the essence of Socrates should feature the Eiffel Tower, and so modal essentialism is extensionally inaccurate. A generalization response will not suffice here. Whilst properties like 'essentially being such that $a \neq b$ ' $([\varepsilon \lambda x(a \neq b)], a)$ can be generalised away (because $(x)([\varepsilon \lambda y(a \neq b)], x)$ is true), the same cannot be said for $a$ 'essentially being distinct from $b^{\prime}([\varepsilon \lambda x(x \neq b)], a)$. This remains an (according to Fine at least) undesirable essential property of $a$. It cannot be generalised away because not everything is such that it is distinct from $b$, namely, $b$ is not distinct from $b$. However, we might avoid the problem using the constitutive/consequential distinction, by admitting that it is essential to $a$ that $\langle a \neq b\rangle$, but that it is merely consequentially so.

Under Fine's definition of consequential essence, $\langle a \neq b\rangle$ is part of $a$ 's consequential essence iff it is a logical consequence of some more basic part of $a$ 's essence. Any particular instance of $a$ being essentially distinct from something (excluding examples like the distinctness of points in Euclidean space, where it is arguably constitutive) follows from $a$ being essentially distinct from everything that is not $a((x)(x \neq a \rightarrow([\varepsilon \lambda y(y \neq x)], a)))$. Furthermore, one might think it follows from the self-identity of $a$ that it should be distinct from everything else, thus placing the claim that $a$ is distinct from $b$ in the consequential essence of $a$ if it is part of the constitutive essence of $a$ that it is self-identical. ${ }^{28}$

There is a problem with using Fine's approach here because of how he responds to a potential regress in his position resulting from the difference between an object having a self-relating property and having a reflexive property (Fine 1995a). A property is self-related if that property involves the object that instantiates it (e.g. $a^{\prime}$ s property 'being identical to $a^{\prime}$ ). Corresponding to each self-relating property is a reflexive property (e.g. being self-identical). Fine claims that if an object essentially has a self-related property then it must also essentially have the corresponding reflexive property. When a relation features in the essence of an object, whatever the object is linked to by that relation also features in the object's essence. An object that essentially has a self-related property features in its own essence. Since Fine (1995a) claims that an object is dependent not only on the existence of those objects that feature in its essence, but on their essences as well, when an object features in its own essence its identity is presupposed in its essence. This results in circularity unless the inclusion of the self-relating property can be attributed to the inclusion of its reflexive counterpart. The reflexive property gives no mention of any object, and thus its inclusion in the essence of an object doesn't result in any such circularity. Essentially having the corresponding reflexive property provides a basis

\footnotetext{
${ }^{28}$ Not everyone would agree that self-identity is essential to $a$. The existence of such disagreement lends weight to my interpretation of the wider debate.
} 
by which the object can be non-circularly said to essentially have the self-related property. However, in accordance with the generalisation response Fine gives in order to render consequential essence suitable for his purposes, any property that is universally instantiated is generalised out from the essence of any object. Self-identity is a universally instantiated reflexive property, and so is generalised away, but without being essentially self-identical, $a$ cannot be essentially such that it is identical to $a$ $([(\varepsilon \lambda x)(x=a)], a)$. As such, $a$ can neither be essentially self-identical, nor essentially identical to $a$.

Now consider CONSITUTIVE* . The necessity of non-identity statements ensures that $\langle a \neq b>$ is still essential to $a$. Being essentially distinct from $b$ is harmless if it is only part of the consequential essence of $a$. It is worth noting that, unlike the original distinction, in the current distinction the consequential essence of an object does not depend on the constitutive essence of that object. According to CONSTITUTIVE*, that $a$ is self-identical is a part of $a$ 's constitutive essence because $\langle a=a\rangle$ is true because of $a$ in every world in which $a$ exists. If the modal essentialist chooses to generalise away universally instantiated properties from objects' essences, then it is not essential to $a$ that it is selfidentical. However, this has no effect on whether $\langle a \neq b>$ is part of $a$ 's consequential essence. Whilst $a$ is necessarily such that $\langle a \neq b\rangle$, this is not solely because of $a$ in every world in which $a$ exists, it is because of $a$ and $b$. As such, $\langle a \neq b>$ is part of $a$ 's consequential essence; this is regardless of what is in its constitutive essence.

Even if it were constitutively essential to $a$ that it be distinct from $b$, what harm would this do? Fine's arguments rest on the assumption that if the results of modal essentialism differ from our pretheoretical understanding of essence then they are shown to be extensionally inaccurate, and so false. In discussing Case 3, I consider the claim that this is not as problematic as Fine takes it to be.

\subsection{Case 3}

Case 3 pointed out that under the conditional modal account every object exists essentially because it exists in every world in which it exists. Fine claims that this is absurd, and as such modal essentialism must be mistaken. How we should view this criticism depends on how we interpret the larger debate between modal and neo-Aristotelian essentialism.

Fine accuses the conditional modal essentialist of predicating objects with essential existence, and it is true that they do this. Fine takes this to be problematic because he has a pre-theoretic idea of what such a claim amounts to. However, accusing the modal essentialist of making a predication that is only problematic by the neo-Aristotelian essentialist's light seems to be little more than begging the question against the modal essentialist. Within the context of my proposed interpretation of the debate, essential existence must be judged by the modal essentialist's lights. For the modal 
essentialist, ubiquitous essential existence is exactly what we should expect. It is simply the claim that every object exists in every world in which it exists. ${ }^{29}$ It is a trivial consequence of the theory, and is neither obviously problematic, nor of any particular interest. Under neo-Aristotelian essentialism, essential existence is allegedly problematic, but we are not committed to it. Under modal essentialism, we are committed to essential existence, but it is not problematic.

However, this is not the project that Fine is engaged upon. Fine (1995a 58) has a pre-conceived understanding of what it is for something to essentially exist, and he thinks this pre-theoretical understanding of essence renders the essential existence of everyday objects absurd. As such, any account of essence that says that everyday objects exist essentially is not only extensionally inaccurate, but committing an absurdity.

What makes the essential existence of everyday objects absurd? Fine does not make it clear why it should be problematic for Socrates to essentially exist. Presumably he thinks that it conflicts with our intuitions about essence, and that it is thus obvious. He merely asserts that 'we do not want to say that [Socrates] essentially exists (Fine 1994 5)'.

Here are some potential worries that may motivate Fine's repudiation of essential existence: First, including existence in the essence of a thing tells us nothing about what it is to be that thing; at least it tells us nothing unique about what it is to be that thing. This is true, but existence differs from set membership and non-identity claims. Existence is at least relevant to a thing in a way that the others are not. It is certainly true that Socrates could not be Socrates without existing.

Second, one may claim, as Kant (1781) does, that existence is not a real property, but rather a precondition for having properties, and as such is not an appropriate constituent for an object's essence. It is unlikely that this is what Fine is thinking, as he is willing to countenance some things having essential existence (God, for example). Furthermore, if existence is not a true property, then it poses no threat to the modal essentialist.

Third, Fine may be worried about some kind of Anselmian ontological argument that would allow the actual or necessary existence of a thing to follow from its essentially existing (Anselm 1078). This seems an unlikely interpretation of Fine's motivation for the same reasons that modern philosophers are generally not too worried about theistic ontological arguments. Furthermore, whilst $a$ being essentially $F$ entails that it is necessarily $F$, the intended form of necessity is only the weakened Kripke necessity, whereby $a$ is necessarily $F$ if it exists. There is no sense in which accepting the neoAristotelian essential existence of $a$ commits one to the actual existence of $a$.

Fourth, one may be concerned that if everything essentially exists then there is no distinction between that which essentially exists and that which exists only accidentally. This concern rests on

${ }^{29}$ Wildman (2013) also recognises this, describing it as 'a banality of the highest order'. 
equivocation about the meaning of essentialist claims. If 'essentially' were synonymous with 'necessarily', then indeed there would be a problem with a position that could not distinguish between those things that exist essentially and those that do not. However, this is not the neo-Aristotelian position, and I can see nothing built into our understanding of essence (as presented by Fine) that supports the need for such a distinction, let alone any cause to see the lack of one as absurd.

Fine faces a dilemma. Either there is no one well understood notion of essence and the different accounts are presenting rival notions that might explain what we mean when we make essentialist claims, or both accounts are trying to provide an account of a well understood notion. If one chooses the former then Fine is begging the question against the modal essentialist because whilst it is true that everything exists essentially, this is not a problematic, or even interesting conclusion considering what this means according to the modal essentialist's position. If one chooses the latter then it is not even clear what is supposed to be problematic about essential existence. There is no obvious source or explanation of the absurdity that Fine ascribes. Of course, the provision of a good reason why essential existence is problematic would reinstate the criticism's force. However, it is not clear what form such a reason would take.

Prima facie there are no evident data to support the claim that we possess a pre-theoretical understanding of essence sophisticated enough that it informs us on whether or not objects essentially exist. Views on this appear to be informed solely by theory (because without a theory we don't even know what it means for something to exist essentially), in which case essential existence is a weak tool with which to criticise the modal essentialist. The same can be said for the alleged problem from Case 2. If objects are essentially distinct from each other, this is only really problematic under the first interpretation of the debate. A significant part of why Fine finds it problematic is because of his views on dependence. According to Fine (1995a; 1995b; see also Wilson [forthcoming]), an object is ontologically dependent on those objects that feature in its essence. This makes it problematic, as it would be odd for Socrates to be ontologically dependent on the Eiffel Tower. However, such an understanding of dependence is contingent upon accepting Fine's essentialism, so again it seems that the problem begs the question in Fine's favour.

\subsection{Case 4}

Case 4 claimed that it is essential to \{Socrates\} that it contain Socrates, but not essential to Socrates that he be a member or \{Socrates\}. Since modal essentialism cannot account for this asymmetry it is extensionally inaccurate. The first concern with this kind of example is that it requires the use of contentious and unusual metaphysical entities such as sets. One might think that if the concerns 
highlighted are legitimate then they should be demonstrable through more everyday examples. Fine's other cases involve objects like Socrates and the Eiffel Tower, both of which are thoroughly mundane. The case of Socrates and \{Socrates\} merely demonstrates the desired asymmetry well, and for the reader who is not convinced by the subject matter, Fine has three other cases that should firmly press the point to satisfaction. However, the above considerations demonstrate that Fine's other cases are far from conclusive, and left on its own, the Socrates/\{Socrates\} case loses much (though not all) of its force..$^{30}$

Fine's approach is to claim that the intensional notion of essence is not co-extensive with our intuitive understanding of essence. However, if the modal essentialist takes the essence of an object to be its modal profile, then set membership doesn't seem like an unreasonable topic at which to bite the bullet and reject the intuitions that Fine considers paramount.

This links back to the metaphysical contentiousness of the example at hand. Not only does the criticism require that one believe in such things, but it requires that our pre-theoretical understanding should be sufficiently developed to inform us about their essences and how the essences of everyday objects relate to them. It seems outlandish to think that this should be the case. There is little reason to think that intuition should be anything more than a guide when considering the metaphysics of sets and personal identity. Intuition furnishes us with no more decisive information about set theory or advanced metaphysics than it does about particle physics or anatomy. To apply our opinions about Socrates' beard to the metaphysics of sets requires that we endorse a theory based on those opinions. As soon as we do that we beg the question in favour of whatever that theory is.

\section{Conclusion}

Even if we interpret the debate on essentialism as between rival attempts to give metaphysical explanations for an accepted base of pre-philosophical opinions, the cases Fine presents are not decisive in showing the inadequacy of the modal account. The modal essentialist can employ tactics (inspired by Fine's developments of his position) to respond to Cases 1 and 2. Case 3 is not evidently problematic, and Case 4 is based on assumptions about subject matter for which pre-philosophical opinion cannot provide legitimate information.

How best to interpret Fine's work then? If we take Fine's four cases as definitive of a more finegrained notion of essence, rather than descriptive of a pre-theoretical one, then the virtues of Fines' position come into sharp relief. Neo-Aristotelian essentialism integrates better with a wider

\footnotetext{
${ }^{30}$ The same can be said for related examples such as Tahko and Lowe's (2015) example of Socrates and the temporally extended event or process that was his life, the discussion of which immediately relies on adopting philosophical ideas about what a life might be.
} 
metaphysical program. It has the potential to play a role in a unified theory of necessity, ground, and ontological dependence. It makes essence a more interesting topic for the metaphysician. Rather than being an uninteresting special case of necessity, essence plays a central explanatory role in our theory of the world. This is the starting point from which discussions of essence should take place.

\section{References}

Adams, S. 2016. A New Paradox of Omnipotence. Philosophia, pp.1-27.

Anselm, Saint, Archbishop of Canterbury. 1078/1974: Proslogion. In Hopkins, J. \& Richardson, H. (eds. \& trans.) Anselm of Canterbury Vol 1. London: SCM Press Ltd.

Carroll, L. 1895. What the Tortoise said to Achilles. Mind 4(14), pp.278-280.

Correia, F. 2006. Generic Essence, Objectual Essence, and Modality. Noûs 40 (4):753-767.

Correia, F. 2007. (Finean) Essence and (Priorean) Modality. Dialectica 61(1), pp.63-84.

Correia, F. 2012. On the Reduction of Necessity to Essence. Philosophy and Phenomenological Research 84(3), pp.639-653.

Cowling, S. 2013. The Modal View of Essence. Canadian Journal of Philosophy 43 (2), pp.248-266.

Della Rocca, M. 1996. Essentialism: Part 2. Philosophical Books 37(2), pp.81-89.

Denby, D. 2014. Essence and Intrinsicality. In Francescotti, R (ed.), Companion to Intrinsic Properties. De Gruyter, pp.87-109

Fine, K. 1994. Essence and Modality. Philosophical Perspectives 8, pp.1-16.

Fine, K. 1995a. Senses of Essence. In Sinnott-Armstrong, W. Raffman, D. \& Asher, N. (eds.), Modality, Morality and Belief. Essays in Honor of Ruth Barcan Marcus. Cambridge: Cambridge University Press.

Fine, K. 1995b. Ontological Dependence. Proceedings of the Aristotelian Society 95, pp.269-290.

Fine, K. 1995c. The Logic of Essence. Journal of Philosophical Logic 24(3), pp.241-273.

Fine, K. 2000. Semantics for the Logic of Essence. Journal of Philosophical Logic 29(6), pp.543-584.

Fine, K. 2007. Response to Fabrice Correia. Dialectica 61(1), pp.85-88.

Fine, K. 2015. Unified Foundations for Essence and Ground. Journal of the American Philosophical Association 1(2), pp.296-311.

Gorman, M. 2005. The Essential and the Accidental. Ratio 18(3), pp.276-289. 
Hale, B. 2013. Necessary Beings: An Essay on Ontology, Modality, and the Relations Between Them. OUP Oxford.

Kant, I. 1781/2007. The Impossibility of an Ontological Proof of the Existence of God. In Kant, I. Critique of Pure Reason. Basingstoke: Palgrave Macmillan, pp.500-507.

Koslicki, K. 2012a. Varieties of Ontological Dependence. In Correia, F \& Schnieder, B (eds.), Metaphysical Grounding: Understanding the Structure of Reality. Cambridge University Press.

Koslicki, K. 2012b. Essence, Necessity, and Explanation. In Tahko, T (ed.), Contemporary Aristotelian Metaphysics. Cambridge University Press pp.187-206.

Lowe, E. J. 2008. Two notions of being: Entity and essence. Royal Institute of Philosophy Supplement $83(62): 23-48$.

Oderberg, D. 2007. Real Essentialism. Routledge.

Shalkowski, S. 2008. Essence and being. Royal Institute of Philosophy Supplement. 83 (62):49-63.

Skiles, A. 2015. Essence in Abundance. Canadian Journal of Philosophy. 45 (1), pp.100-112.

Tahko, T. E. \& Lowe, E. J. 2015. Ontological Dependence. Stanford Encyclopedia of Philosophy.

Wildman, N. 2013. Modality, Sparsity, and Essence. Philosophical Quarterly 63(253), pp.760-782.

Wildman, N. 2016. How (Not) to be a Modalist about Essence. In Jago, M. \& Barker, S. (eds.) Reality Making: Essence, Fundamentality, \& Grounding, Oxford University Press

Wilson J. (forthcoming). Essence and Dependence. In Mircea D (ed.), Metaphysics, Meaning, and Modality: Themes from Kit Fine. Oxford

Zalta, E.N. 2006. Essence and Modality. Mind 115(459), pp.659-693. 